Original Article

\title{
ASSESSMENT OF THE POSSIBLE CAUSES OF DIABETES MELLITUS DEVELOPED IN PATIENTS POST COVID-19 TREATMENT IN A TERTIARY CARE HOSPITAL
}

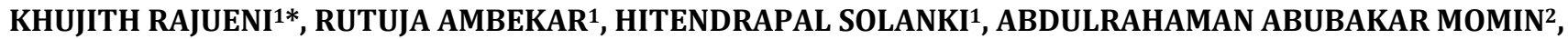 \\ SUNITA PAWAR ${ }^{3}$
}

1 Poona College of Pharmacy, Bharati Vidyapeeth University, ${ }^{2}$ Department of Biochemistry Bharati Vidyapeeth (DTU) Medical College, Pune India, ${ }^{3}$ Department of Clinical Pharmacy, Pharm D, Poona College of Pharmacy, Bharati Vidyapeeth University Email: khujith.rajueni@gmail.com

Received: 23 Jun 2021, Revised and Accepted: 28 Jul 2021

\begin{abstract}
Objective: Novel COVID-19 virus is extensively being studied for its long-term effects. A predominant trend of development of Diabetes Mellitus (DM) in Covid-19 patients is being observed, and hence further relation is explored in this study.

Methods: This is an observational inductive retrospective study conducted for four months in a tertiary care hospital. The study included subjects who recovered from COVID-19 and were treated post-COVID-19 in the hospital. The subjects who had stable glucose counts were excluded. The data obtained from the medical record department encompassed demographic details and clinical data of the patient. The data were tabulated, and observations were reported using descriptive analysis.
\end{abstract}

Results: Among 5632 admitted patients for COVID-19, 694 came for follow-up. 105 patients were re-admitted, but 11 had newly developed DM, and 14 observed uncontrolled DM managed by medical attention. The reported incidence rate in Newly-Diagnosed DM was 0.195\%, and the person above $41 \mathrm{y}$ was at greater risk. Similarly, the incidence rate in Uncontrolled-DM was $13.33 \%$, and persons above $47 \mathrm{y}$ were at greater risk. It was found that both these categories of patients had comorbidities, and the development of this was seen between the 25th-40th day. In both cases, males were more prone than females.

Conclusion: The study reports a bi-directional relationship between Covid-19 and DM. The use of steroids may have stepped-up this relationship. Cautious use of steroids, changes in the hospital formulary, and further quantitative clinical investigations are primary recommendations that may prevent such episodes.

Keywords: Covid-19, Type 2 diabetes mellitus, Post-covid, Uncontrolled diabetes mellitus, Newly diagnosed diabetes mellitus, Steroids, Prednisolone

(C) 2021 The Authors. Published by Innovare Academic Sciences Pvt Ltd. This is an open-access article under the CC BY license (https://creativecommons.org/licenses/by/4.0/)

DOI: https://dx.doi.org/10.22159/ijpps.2021v13i9.42508. Journal homepage: https://innovareacademics.in/journals/index.php/ijpps.

\section{INTRODUCTION}

Covid-19, being a relatively recent virus, has much scope and research for analysis. Evidence regarding COVID-19 has yet been emerging, and current information has given researchers the latest perspective regarding it. Such is observed as a relationship between Covid-19 and Diabetes Mellitus. This newly observed relationship between Diabetes Mellitus and COVID-19 is initially seen as increased Blood glucose levels followed by other clinical symptoms [1,2].

It is important to note a peculiar relationship between age and the commencement of Diabetes Mellitus [3]. Individuals with Diabetes Mellitus, Hypertension, and severe Obesity (BMI less than 40 $\mathrm{kg} / \mathrm{m} 2$ ) are more likely to be infected. They are at higher risk for complications and death from COVID-19 [4]. Investigations using meta-analysis or double-blinded methods have been used so far to objectively examine the relationship [5]. Between COVID-19 and Diabetes, there is a bidirectional/relationship [6]. Diabetes is linked to a higher risk of extreme COVID-19. On the other hand, in patients with Covid, however, new-onset diabetes and serious metabolic complications of pre-existing diabetes, such as diabetic ketoacidosis and hyperosmolarity, necessitating extremely high insulin doses, have been observed [7-9].

There have been potential mechanisms that may comprehend this relationship, especially between ongoing inflammation and insulin resistance [10]. Suffices to say, the COVID-19 virus has a very expeditious spreadability, and due to its contagious nature, influenza-related mortality is seen [11]. Evidence suggests that Diabetic patients tend to observe symptoms of either severe acute respiratory syndrome (SARS) or Middle East Respiratory Syndrome (MERS) but definitely not limited to the traditional symptoms observed $[12,13]$. Such cases have been seen in India. Still, less acknowledged and known about as well as less studied [14]. Quantifiable data regarding the same can be obtained from the United Kingdom, the United States of America, and other first-world countries [15]. Developing countries have also produced substantial evidence, but it is yet subject to debate [16].

The study intends to incur fresh perspective and analysis, to conclude productive data on new-onset hyperglycemia, diabetic ketoacidosis, which was being increasingly described among postCOVID-19 patients without a previous history of diabetes, albeit with no significant morbidity. The study assesses the underlying reasons for the increase in diabetes mellitus in post-COVID-19 recovered patients in a tertiary care hospital.

\section{METHODS AND MATERIALS}

The observational inductive retrospective study was conducted for a period of 4 mo, i.e., from December 2020 to April 2021, in a tertiary care hospital at Pune city in Maharashtra, India. The ethical clearance for the study was obtained from Bharati Vidyapeeth Deemed to be University Medical College (EC certificate no: BVDUMC/IEC/92). The study included subjects that recovered from SARS-Cov-2 and were treated post-Covid in the same studied hospital. The data was collected of such subjects whose glucose change was observed and confirmed by the Registered Medical Practitioner based on WHO, IDF, and ADA criteria [17].

The excluded subjects were either were not hospitalized due to COVID-19 or, before hospitalization, had an unstable glucose count. Considering these inclusion and exclusion criteria, the data of 25 subjects were identified. The data of the identified subjects were obtained from the Department of Medical Records, separating them from subjects who did not fulfill the inclusion criteria. The data 
collected encompassed demographic details of the subjects, the patient's comorbidities, the drugs prescribed, the clinical laboratory reports, the previous history of the patients, and the medication history. The mentioned information was being collected in a patient profile form. This patient profile form was prepared on the standardized technique offered by several studies on same and modified on pilot testing to qualify the need of the study [18]. The data obtained from the patient profile form was tabulated on the grounds of precision of the obtained data and evaluated with the research papers that had been established. These statistics helped analyze the data to identify the result. A co-relation was attempted between the drugs, the laboratory report, the history of the subject, and Covid - 19. The incidence rate was obtained from the traditional formula.

Incident rate $=[$ number of cases $/$ number of patients admitted $] \times 100$

\section{RESULTS}

The present study was aimed to find out the incidence of diabetes mellitus in COVID-19 patients after the infection and its possible causes. A total of 5632 COVID-19 patients were admitted and treated for COVID-19 until the end of April 2021, and the records showed 694 patients came for follow-up, of which 105 patients were re-admitted for some complications till March 2021. Of the remaining 589 patients, one patient who had a history of vertigo mentioned newly diagnosed Diabetes Mellitus, which the local general physician managed. Therefore, pre and post-COVID-19 hospitalization, only one follow-up patient had been seen with Newly Diagnosed Diabetes Mellitus. No special investigation was done on patients who came for follow-up in the out-patient-department since it was not a part of the study.

Of the 105 patients who were admitted, 79 patients had Diabetes Mellitus. Among 105 patients, there were 11 patients, before COVID19 infection, who had no history of diabetes. Still, it developed as a complication after the treatment/discharge from Covid-19, for which the patients were re-admitted. Of which 65 patients had a history of diabetes mellitus, 14 of these observed sudden spikes in blood glucose level post-treatment, which was the reason for re-admission.
The other complications (comorbidities) apart from Diabetes mellitus for which those 105 patients were admitted are depicted in table 1.

Table 1: Complication during re-admission present in COVID-19 patients

\begin{tabular}{ll}
\hline Complications & N [\%] \\
\hline Abnormalities in ECG & 2 \\
Chest pain & 6 \\
Cough & 9 \\
Difficulty in breathing & 9 \\
Difficulty in thinking or concentrating & 2 \\
Dizziness & 1 \\
DKA & 6 \\
Exacerbation & 4 \\
Fatigue & 2 \\
Fever & 7 \\
Follow up & 33 \\
High BP & 6 \\
Hyperglycemic episode & 3 \\
Joint or muscle pain & 5 \\
Pneumonia & 5 \\
\hline
\end{tabular}

It was observed that certain patients on admission did not have Diabetes Mellitus, which was confirmed by an on-admission clinical investigation, and physicians confirmed the diagnosis. The key findings of the same would be mentioned in a crux. Prednisolone was the only drug that was seen to have caused hyperglycemia. Secondly, persons above the age of 41 y developed Diabetes Mellitus. Thirdly, the incidence rate of persons who acquired Diabetes Mellitus after treatment of Covid-19 was $1.953 / 1000$ persons in the tertiary care hospital. [11/5632 x $100=0.195 \%]$.

The demographic, clinical, and bacteriological profiles of patients readmitted after COVID-19 treatment $(n=105)$ are outlined in table 2 .

Table 2: The demographic, clinical, and bacteriological profile of patients re-admitted after COVID-19 treatment (n=105)

\begin{tabular}{|c|c|c|}
\hline Parameters & & $\mathbf{N}$ \\
\hline $\mathrm{AGE}[\mathrm{mean} \pm \mathrm{SD}]$ & & $48.63 \pm 19.67$ \\
\hline \multirow[t]{2}{*}{ Gender } & Male & $75 \%$ \\
\hline & Female & $25 \%$ \\
\hline Hba1c $[$ mean $\pm S D]$ & & $6.21 \pm 0.86$ \\
\hline Hba1c on re-admission [mean \pm SD] & & $7.84 \pm 6.75$ \\
\hline \multirow[t]{14}{*}{ History of } & Diabetes & 76 \\
\hline & Hypertension & 19 \\
\hline & Pneumonia & 30 \\
\hline & IHD & 7 \\
\hline & Fatty liver & 7 \\
\hline & Asthma & 6 \\
\hline & Myt. Gravis & 3 \\
\hline & Rheumatoid arthritis & 3 \\
\hline & Rheumatic valvular heart disease & 1 \\
\hline & Hypokalemia & 1 \\
\hline & CKD & 1 \\
\hline & Bipolar & 2 \\
\hline & DKA & 1 \\
\hline & Anemia & 5 \\
\hline \multirow[t]{6}{*}{ Co-infection } & E. Coli & 9 \\
\hline & Klebsiella pneumonia & 10 \\
\hline & Enterococcus faecium & 2 \\
\hline & Enterococcus hominis & 2 \\
\hline & Staphylococcus aureus & 6 \\
\hline & Proteus mirabilis & 4 \\
\hline
\end{tabular}

The male patients were found to be more prone to post-Covid Diabetes Mellitus than females. (Male: Female = 9:2) in the present study, more males had acquired diabetes mellitus after the COVID19 infections. Also, the patients with pre-existing comorbidities, such as cardiovascular disease and Rheumatoid Arthritis, were seen to have developed Diabetes Mellitus. The diagnosis of diabetes among these patients was made between the period of the 25 th to the 40th day after their first discharge from the hospital. 
On the contrary, some patients were admitted due to Covid-19 but possessed a history of Diabetes Mellitus. A certain number of these patients did see a spike or surge in the glucose levels after the treatment of Covid - 19. This surge or spike was controlled only by medical attention and insulin. Persons above the age of $47 \mathrm{y}$, who had a history of Diabetes Mellitus before hospitalization, observed this spike or surge. The demographic and laboratory findings in patients with sudden blood glucose spikes having a history of diabetes mellitus are listed in table 3 . The incidence rate of persons whose blood glucose level observed a surge or spike after the treatment of Covid-19 was $13.33 / 1000$ persons in the tertiary care hospital. $(14 / 105 \times 100=13.333 \%)$

Table 3: The demographic and laboratory findings in patients with sudden blood glucose spikes having a history of diabetes mellitus

\begin{tabular}{lll}
\hline Parameters & & With a history of DM (N=76) \\
\hline Age [mean \pm SD] & & $58 \pm 10.27$ \\
Gender & Male & 61 \\
& Female & 15 \\
Hba1c [mean \pm SD] & & $6.42 \pm 0.71$ \\
Hba1c on re-admission [mean \pm SD] & Hypertension & $8.55 \pm 7.80$ \\
History of & Pneumonia & 19 \\
& IHD & 27 \\
& Fatty liver & 7 \\
& Asthma & 7 \\
& Myt. Gravis & 5 \\
& Rheumatoid arthritis & 3 \\
& Rheumatic valvular heart disease & 1 \\
& Hypokalemia & 1 \\
& CKD & 1 \\
Co-infection & BIPOLAR & 1 \\
& DKA & 2 \\
& Anemia & 1 \\
& E. Coli & 4 \\
& Klebsiella pneumonia & 7 \\
\end{tabular}

The Co-infection findings in patients with newly diagnosed diabetes mellitus and patients with sudden blood glucose spikes having a history of diabetes mellitus are tabulated in table 4.

Table 4: The Co-infection findings in patients newly diagnosed with diabetes mellitus and patients with sudden blood glucose spikes having a history of diabetes mellitus

\begin{tabular}{llll}
\hline & Organism & $\begin{array}{l}\text { With newly diagnosed DM, covid-19 patients } \\
(\mathbf{n = 1 1 )} \mathbf{~ N}\end{array}$ & $\begin{array}{l}\text { With a history of DM, covid-19 patients (n=14) } \\
\text { N }\end{array}$ \\
\hline Co-infection & 2 & 3 \\
& E. Coli & 3 & 1 \\
& Klebsiella pneumonia & 1 & 0 \\
& Staphylococcus hominis & 1 & 0 \\
& Staphylococcus aureus & 1 & 1 \\
& Proteus mirabilis & 0 & 1 \\
Enterococcus faecium & 0 & \\
\hline
\end{tabular}

\section{DISCUSSION}

Empathy from the international media surges towards India. Looking onto the administration, India sulks to save lives. Hence, the Indian scenario of Covid-19 draws international attention [19, 20].

The repercussion of COVID-19 infection has been a subject matter of debate and discussion. There have been several studies working on this matter and several more yet to publish. Most drugs used during Covid-19 were already in used in the market. There is a lack of studies to claim the side effects of these drugs causing a metabolic disorder, especially in classical antivirals and steroids where the patients have shown improvement after hospitalization. An animal study on cats proved that prednisolone induced diabetes mellitus when used over a long period [21]. This may indicate that a particular category of patients is susceptible to induced diabetes mellitus. This is a similar trend observed where Mucormycosis due to prednisolone's immunocompromising nature. The probable mechanism of action could be that in human monocytes, elevated glucose levels directly increase SARS-CoV-2 replication, while glycol sis supports SARS-CoV-2 replication by generating mitochondrial reactive oxygen species and hypoxia-induced factor $l \alpha$ activation. Therefore, high blood sugar can cause the virus to spread. Consistent with this hypothesis, it has been established that hyperglycemia or the history of TIDM and T2DM are independent predictors of the morbidity and mortality of SARS patients [10]. In addition, the simultaneous use of T2DM in MERS-CoV-infected mice can cause immune response disorders, which can lead to severe immune responses and a wide range of lung diseases. Diabetic patients usually have a higher severity of SARS-CoV-2 infection than non-diabetic patients, and poor blood sugar control indicates higher drug doses, hospital needs and mortality [15]. SARS Covid-19 infections may act as worsening causes for diabetic patients. As mentioned, it can be due to acute metabolic complications by the effect on $ß$-cell functioning. This effect on p-cell functioning may cause several disorders diabetic ketoacidosis, hyperglycemia in individuals with unknown history of diabetes, and potentially new-onset Diabetes [23].

Several post-Covid hospitalization issues are pulsing around. These include non-restorative sleep, chronic fatigue syndrome, cognitive dysfunction, autonomic dysfunction, etc. These all could be termed as 'POST-COVID SYNDROME' [24]. As per the International Diabetes Federation (IDF) Diabetes Atlas, the prevalence of diabetes Mellitus above the age of 19 and below 80 y is 6.6\% (The year 2010). India, also known as the Diabetes capital of the world, holds an estimate of 
50.8 million people suffering from the same as of 2010 [25]. Diabetes has been a concern since its discovery. The discovery of Covid-19 has simply worsened it.

The study tried to look into the presence of both simultaneously as well the upcoming Diabetes post-COVID-19 hospitalizations. A symbolic link could be a metabolic disturbance that may be caused due to the Covid-19 infection-a metabolic disorder that lasts probably a lifetime. The body has not yet recovered from the damage after being tested Covid-19 negative. It is only after $45 \mathrm{~d}$ that there may be less possibility of this physical health crisis. Usually, patients are called for follow-up after $30 \mathrm{~d}$. This practice is now scientifically more explicit than before. Patients may observe poor health during a specific phase post-Covid. It should be highly recommended to the patient's caretakers that the post-covid phase is equally crucial as Covid 19 positive phase.

Regarding infections, it would also be a possibility that due to several drugs having an interaction, there is the presence of newly diagnosed Diabetes Mellitus or diabetes spike. We can observe a monodirectional relationship in polypharmacy and diabetes mellitus leading to infection susceptibility [26]. There is no observed relationship between acquisition of a bacterial infection and Diabetes Mellitus on further investigation of both these categories. Still, it is evident that patients who have DM are more susceptible to infection [27].

Prednisolone is a drug through which a glucose spike is observed during the course of its administration, but once the drug is withdrawn, this spike is not observed any further after the wash-off period $[28,29]$. BMI of every subject was obtained to establish a relationship between BMI and Covid-19, and an association was observed [30]. The analysis reports an association between Obesity with the possibility of acquisition or spike in diabetes Mellitus $[31,32]$. It cannot be denied that the key attention for this permanent diabetes mellitus is on steroids due to its well-known symptom of hyperglycemia.

Substantial literature claims that several drugs may have interacted and caused a metabolic disorder, but prednisone might have been the key drug [33]. The right conditions for metabolic disease are age, weight, diet, and other physical and environmental factors. Since DM has a bidirectional relationship with COVID-19, maybe an added-on factor to these conditions [34]. Considering this bi-directionality in COVID-19, there is a possibility that this bi-directionality may have also been reflected in metabolic disorders, i.e., Diabetes Mellitus, as seen in the case of mucormycosis [35]. A spike in the patient's glucose levels who required hospitalization may have been due to a possible result of the unfavorable outcomes.

\section{CONCLUSION}

Patients may have acquired DM or observed a spike due to steroids, but this may have become a permanent condition due to the ongoing health-related quality of life of the patient. It can also be kept open as a possibility that several drugs may have interacted under the 'favorable' conditions for a metabolic disorder.

Further investigation must be insisted on the use of steroids in patients with Covid-19. The medical fraternity is liable when is a disease occurs due to a drug-iatrogenesis. Changes in the formulary and the line of treatment is essential.

Since the incidence rate is minuscule but adequate, which means that probably the event is happening, but it is not given enough attention. The guidelines for non-communicable diseases, especially DM, need to be reviewed by the Indian Council of Medical Research concerning Covid-19.

\section{ACKNOWLEDGEMENT}

The study acknowledges Dr Idris Dawaiwala for his contribution time and again.

\section{LIMITATION OF STUDY}

There are limitations to the study that is conducted, such as the research was conducted retrospectively, therefore the absence of physical interaction with the patient. The number of subjects admitted at the tertiary care hospital was more male than female. Patients who did not turn up for follow-up or had gone to their local physician for a follow-up could not be learned. Therefore, limited access to follow-up patients was observed.

\section{FUNDING}

Nil

\section{AUTHORS CONTRIBUTIONS}

The manuscript was conceived by Rutuja A, Khujith R, and Hitendrapal S, who also prepared the manuscript. Prior to submission, all of the authors studied the literature, made significant revisions, and agreed on the final description.

\section{CONFLICT OF INTERESTS}

\section{Declared none}

\section{REFERENCES}

1. Ren H, Yang Y, Wang F, Yan Y, Shi X, Dong K, et al. Association of the insulin resistance marker TyG index with the severity and mortality of COVID-19. Cardiovascular Diabetology 2020;19:58.

2. Rubino F, Amiel SA, Zimmet P, Alberti G, Bornstein S, Eckel RH, et al. New-onset diabetes in covid-19. New England J Med 2020;383:789-90.

3. Suastika K, Dwipayana P, Siswadi M, Tuty RA. Age is an Important risk factor for type 2 diabetes mellitus and cardiovascular diseases. In: Glucose Tolerance. InTech; 2012.

4. Fang L, Karakiulakis G, Roth M. Are patients with hypertension and diabetes mellitus at increased risk for COVID-19 infection; 2020. Available from: https://doi.org/10.1016/S2213. [Last accessed on 10 May 2021]

5. Bouhanick B, Cracowski JL, Faillie JL. Diabetes and COVID-19. Therapies 2020;75:327-33.

6. Pal R, Bhadada SK. COVID-19 and diabetes mellitus: an unholy interaction of two pandemics. Diabetes Metabolic Syndrome: Clin Res Rev 2020;14:513-7.

7. Wang W, Lu J, Gu W, Zhang Y, Liu J, Ning G. Care for diabetes with COVID-19:Advice from China. Vol. 12. Journal of Diabetes. John Wiley and Sons Inc; 2020. p. 417-9.

8. Peric S, Stulnig TM. Diabetes and COVID-19: Disease-managementpeople. Wiener Klinische Wochenschrift 2020;132:356-61.

9. P DJ, Kumar N DP, A VM, A R. Alterations of lipid levels may induce the insulin resistance in type two diabetes mellitus: a systemic review. Asian J Pharm Clinical Res 2020;27:9-20.

10. Lim S, Bae JH, Kwon HS, Nauck MA. COVID-19 and diabetes mellitus: from pathophysiology to clinical management. Vol. 17. Nature Reviews Endocrinology. Nature Research; 2021. p. 11-30.

11. Umakanthan S, Sahu P, Ranade AV, Bukelo MM, Rao JS, Abrahao Machado LF, et al. Origin, transmission, diagnosis and management of coronavirus disease 2019 [COVID-19]. Vol. 96, Postgraduate Medical Journal. BMJ Publishing Group; 2020. p. 753-8.

12. Erener S. Diabetes, infection risk, and COVID-19. Vol. 39. Molecular Metabolism. Elsevier GmbH; 2020.

13. Qadrie ZL, Wani Sud, Gautam SP, Khan MKA. Outbreak, epidemiology, therapeutics and prevention of coronavirus disease2019: a review. Int J Curr Pharm Res 2020;323:1824-36.

14. Bansal M, Walia MK. COVID 19-an overview on epidemiology, symptoms, prevention, management, treatmen, $t$ and role of health workers. Int J Appl Pharm 2020;12:36-41.

15. Hartmann Boyce J, Morris E, Goyder C, Kinton J, Perring J, Nunan D, et al. Diabetes and COVID-19: Risks, management, and learnings from other national disasters. Diabetes Care 2020;43:1695-703.

16. Guo W, Li M, Dong Y, Zhou H, Zhang Z, Tian C, et al. Diabetes is a risk factor for the progression and prognosis of COVID-19. Diabetes/Metab Res Rev 2020;36. DOI:10.1002/dmrr.3319

17. World Health Organization, International Diabetes Federation. Definition and diagnosis of diabetes mellitus and intermediate hyperglycaemia: report of a WHO/IDF consultation. 46; 2006.

18. Demanuele F, Hines RM, Walter JR. CPP for family practice use. Six of them are from community practices and ten from teaching units. The Cumulative Patient Profile in Family Practice; 1977. 
19. The Lancet. India's COVID-19 emergency. Lancet [London, England] [Internet]; 2021;397:1683. Available from http://www.ncbi.nlm.nih.gov/pubmed/33965073. [Last accessed on 10 May 2021]

20. Mishra SK, Tripathi T. One year update on the COVID-19 pandemic: Where are we now? Vol. 214. Acta Tropica. Elsevier B. V.; 2021.

21. Nerhagen S, Moberg HL, Boge GS, Glanemann B. Prednisoloneinduced diabetes mellitus in the cat: a historical cohort. J Feline Med Surgery 2021;23:175-80.

22. Sittig KR, Laageide LG, Akhtar Z, Wall GC, Kumar SC. Cutaneous mucormycosis in a chronic lymphocytic leukemia patient on ibrutinib. IDCases; 2021. p. 24.

23. Apicella M, Campopiano MC, Mantuano M, Mazoni L, Coppelli A, del Prato S. COVID-19 in people with diabetes: understanding the reasons for worse outcomes. Vol. 8. The Lancet Diabetes and Endocrinology. Lancet Publishing Group; 2020. p. 782-92.

24. Perrin R, Riste L, Hann M, Walther A, Mukherjee A, Heald A. Into the looking glass: Post-viral syndrome post-COVID-19. Vol. 144. Medical Hypotheses. Churchill Livingstone; 2020.

25. Misra P, Upadhyay RP, Misra A, Anand K. A review of the epidemiology of diabetes in rural India. Diabetes Res Clin Practice 2011;92:303-11.

26. Knapp S. Diabetes and infection: is there a link?-a mini-review. Gerontology 2013;59:99-104.

27. Langford BJ, So M, Raybardhan S, Leung V, Westwood D, MacFadden DR, et al. Bacterial co-infection and secondary infection in patients with COVID-19: a living rapid review and meta-analysis. Clin Microbiol Inf 2020;26:1622-9.
28. Suh S, Park MK. Glucocorticoid-induced diabetes mellitus: an important but overlooked problem. Endocrinol Metab 2017;32:180-9.

29. Shah M, Adel MM, Tahsin B, Guerra Y, Fogelfeld L. Effect of short-term prednisone on beta-cell function in subjects with type 2 diabetes mellitus and healthy subjects. PLoS One 2020;15:e0231190.

30. Gao F, Zheng KI, Wang XB, Sun QF, Pan KH, Wang TY, et al. Obesity is a risk factor for greater COVID-19 severity. Vol. 43. Diabetes Care. American Diabetes Association Inc; 2020. p. E72-4.

31. Zhou Y, Chi J, Lv W, Wang Y. Obesity and diabetes as high-risk factors for severe coronavirus disease 2019 [Covid-19]. Vol. 37. Diabetes/Metabolism Research and Reviews. John Wiley and Sons Ltd; 2021.

32. Heindel JJ, Blumberg B, Cave M, Machtinger R, Mantovani A, Mendez MA, et al. Metabolism disrupting chemicals and metabolic disorders. Reproductive Toxicol 2017;68:3-33.

33. Rao KN, Patil N, Vidyasagar S, Manjunath Holla A. Clinical and biochemical profile of steroid-induced diabetes. Asian J Pharm Clin Res 2016;9:262-6.

34. Pugliese G, Vitale M, Resi V, Orsi E. Is diabetes mellitus a risk factor for Corona VIrus Disease 19 [COVID-19]? Acta Diabetol Springer Verlag Italia 2020;57:1275-85.

35. Mehta S, Pandey A. Rhino-orbital mucormycosis associated with COVID-19. Cureus 2020;12:e10726. 